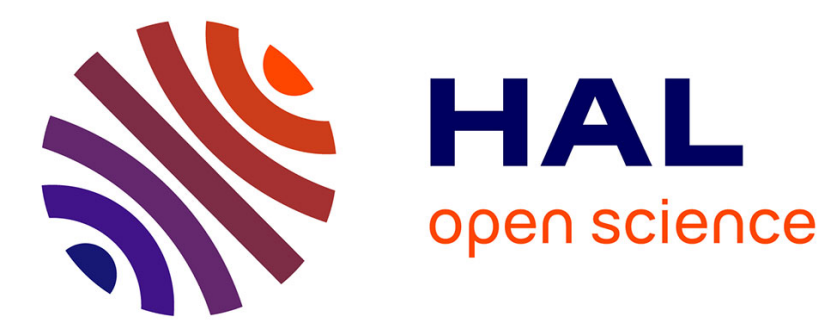

\title{
Large-scale cathodic carboxylation of copper surfaces
} Jacques Simonet

\section{To cite this version:}

Jacques Simonet. Large-scale cathodic carboxylation of copper surfaces. Electrochemistry Communications, 2017, 76, pp.67-70. 10.1016/j.elecom.2017.01.018 . hal-01475819

HAL Id: hal-01475819 https://hal-univ-rennes1.archives-ouvertes.fr/hal-01475819

Submitted on 4 Jul 2017

HAL is a multi-disciplinary open access archive for the deposit and dissemination of scientific research documents, whether they are published or not. The documents may come from teaching and research institutions in France or abroad, or from public or private research centers.
L'archive ouverte pluridisciplinaire HAL, est destinée au dépôt et à la diffusion de documents scientifiques de niveau recherche, publiés ou non, émanant des établissements d'enseignement et de recherche français ou étrangers, des laboratoires publics ou privés. 


\title{
Large-scale cathodic carboxylation of copper surfaces
}

\author{
Jacques Simonet*
}

Laboratoire MaCSE, UMR 6226, Université de Rennes 1, Campus de Beaulieu, 35042 Rennes Cedex, France.

\begin{abstract}
Large scale carboxylation of copper can easily be achieved by reduction of $\mathrm{CO}_{2}$ solubilised in aprotic polar solvents in the presence of tetramethylammonium salts $\left(\mathrm{TMeA}^{+} \mathrm{X}^{-}\right.$ ). Carbon dioxide could be inserted into the metal matrix (presumably in the form of the carbon dioxide anion radical) at high surface concentrations (up to $10^{-7}$ mole $\mathrm{cm}^{-2}$ ), most probably organized in multi-layers. With significant amounts of electricity $\left(>0.1 \times 10^{-2} \mathrm{C} \mathrm{cm}^{-}\right.$ ${ }^{2}$ ), this cathodic procedure leads to an impressive corrosion phenomenon. Importantly, the interfacial carboxylation of copper may efficiently protect the interface against anodic corrosion (gain up to $\Delta \mathrm{E} \approx+1.3 \mathrm{~V}$ ). Moreover, the insertion process is reversible and anodic oxidation leads to release of gaseous $\mathrm{CO}_{2}$. Lastly, the external poly-carboxylated layers can easily be tailored to produce a variety of chemically modified interfaces.
\end{abstract}

*Corresponding author: Tel.: +33-23236292; Fax: + 33-23236732

E-mail address: jacques.simonet@univ-rennes1.fr or jacques.simonet@dbmail.com.

Key Words: Cathodic doping of copper; Carboxylation of copper; Carbon dioxide electroreduction; Electrochemically modified surfaces; Metal-carbonaceous composites.

\section{Introduction}

Carbon dioxide is known to react under a wide range of cathodic processes and many papers have recently been published on its catalytic reduction at different metallic surfaces [1-14]. Contributions based on the reduction of $\mathrm{CO}_{2}$ to methanol, carbon monoxide, methane or salts such as oxalates might appear as a partial solution to decreasing the environmental nuisance of this effluent. The electrochemical reactivity of this molecule might possibly be employed for valorization of this pollutant via reduction processes or other modes of sequestration in conducting solids. Moreover, the electrophilicity of $\mathrm{CO}_{2}$ has also been used to promote efficient reactions with different allotropic forms of carbon under cathodic activation in aprotic media. In this way, cathodically doped graphite, glassy carbon and graphene can be powerfully transformed into carboxylated materials [15-16].

Additionally, a recent development might permit the reduction and/or reversible sequestration of $\mathrm{CO}_{2}$ into transition metals, as recently demonstrated with gold and silver [17, 
18], with the concomitant creation of carboxylated layers at the surface of these metals, allowing facile surface functionalization. Although this work is still in progress, many metals might exhibit similar carboxylation and reversible $\mathrm{CO}_{2}$ sequestration behaviours. The present report on the reactivity of copper should be considered essentially as a preview of the ability of copper to be carboxylated to a large extent. Additionally, this metal, which is of considerable interest in organic chemistry as a catalyst and as a reducing species toward carbon-bromide bonds [19], could be used as an electrode up to $+1.2 \mathrm{~V}$ vs. an $\mathrm{Ag} / \mathrm{AgCl}$ electrode when the surface has been carboxylated and then easily transformed into chemically modified layers. Other materials, including platinum, palladium, rhodium, iron, titanium, cobalt and nickel, appear to show promising results, but are not discussed in this paper. Importantly, in some ways, the cathodic $\mathrm{CO}_{2}$ insertion in copper discussed here may be viewed as a chemically reversible procedure that could possibly be put into practice to selective extract $\mathrm{CO}_{2}$ from certain conducting fluids.

\section{Strategy and experimental conditions}

In the classical chemical literature, the catalytic conversion of carbon dioxide into renewable fuel chemicals $\left(\mathrm{CO}_{2}\right.$ saturated at room temperature in aqueous solutions or in organic polar solvents mixed with proton donors) was generally achieved using smooth transition metal electrodes as catalysts, but rarely with good selectivity [1]. In contrast, a totally different approach is presented here which concerns experiments conducted in dry polar aprotic solvents and containing exclusively tetra-methylammonium salts $\left(\mathrm{TMeA}^{+} \mathrm{X}^{-}\right.$, essentially associated with tetrafluoroborate, sulphate and perchlorate). Iodides, bromides, and chlorides could be used as well, but part of the present study also concerns the behavior of the electrode within the anodic range, and it appears judicious to leave halides aside for the time being. Moreover, tetramethylammonium $\mathrm{TMeA}^{+}$salts were used in the present paper because no $\beta$-protons are available in the TMeA+ cation (ie there is no possibility of a Hofmann elimination) to protonate the $\mathrm{CO}_{2}$ anion radical regarded as the main transient in the electrochemical process. Na+ could also be used, but is not described in this communication. The choice of tetramethylammonium $\mathrm{TMeA}^{+}$salts is very possibly the origin of the successful process described hereafter with $\mathrm{Cu}$. Additionally, the smallsize of the $\mathrm{TMeA}^{+}$ion may increase the rate of insertion inside the solid bulk.

In the present report, $0.1 \mathrm{M}$ solutions of tetramethylammonium tetrafluoroborate in dimethylformamide (DMF) were exclusively employed. Chemicals were purchased from 
Aldrich (synthesis quality). Therefore, DMF was used as received (water content <1000 ppm). All electrochemical experiments were performed under an inert atmosphere by bubbling argon through the solution. The electrolytic solution was saturated with $\mathrm{CO}_{2}$ (purchased from Air Liquide) by bubbling for $5 \mathrm{~min}$ at room temperature. Carbon dioxide was used as a saturated solution in DMF (0.199 $\mathrm{mol} \mathrm{L}^{-1}$ at room temperature [19]).

Potentials are all referred to an aqueous $\mathrm{Ag} / \mathrm{AgCl} / \mathrm{KCl}_{\text {sat }}$ electrode. The electrochemical instrumentation has been described previously [15-16].

The copper electrodes (disk diameter: 1.5 and $2 \mathrm{~mm}$ ) used in the voltammetry have apparent surface areas of 1.8 and $3.2 \mathrm{~mm}^{2}$, respectively. Before use, the electrode surfaces were carefully polished with silicon carbide paper (Struers 500 and 1200) or with Norton polishing paper (type 02 and 03) and rinsed with water, then with alcohol and lastly with acetone. After repeated scans or fixed potential electrolyses, the electrodes and metallic plates (exclusive use of pristine copper of purity 99.98\%) were sonicated for two minutes in water. Finally, before analysis, the electrodes were dried under a hot air flow for about 30s. The coulometry measurements and electrolyses reported in this work were carried out using a three-electrode, two-compartment cell with a total catholyte volume of about $5 \mathrm{ml}$.

\section{Carboxylation of copper}

The copper plates and polished $\mathrm{Cu}$ micro-electrodes were first rinsed with aqueous $0.1 \mathrm{M}$ sulfuric acid, washed with water, and finally dried at $60^{\circ} \mathrm{C}$. They may then be easily carboxylated. When large amounts of $\mathrm{CO}_{2}$ are inserted into the metal, the facile anodic oxidation of $\mathrm{Cu}$ at $\mathrm{E} \geq 0.2 \mathrm{~V}$ should prevent a priori any reliable anodic quantifications that concern superficial concentrations of trapped $\mathrm{CO}_{2}$, as previously noted with gold [18].

\section{Figure 1}

However, under the conditions specified in Figure 1, copper surface carboxylation was successfully achieved in the course of repeated scans. The cathodic reduction (first scan) exhibits two broad steps, the first being assigned to the reduction of the adsorbed $\mathrm{CO}_{2}$. After several scans between $0 \mathrm{~V}$ and $-2.0 \mathrm{~V}$, the electrode surface was totally deactivated, presumably owing to the reaction of the $\mathrm{CO}_{2}$ anion radicals with the copper surface. Fixed 
potential electrolyses carried out with $\mathrm{Cu}$ sheets showed progressive corrosion of the surface (Figure $2 \mathbf{A}$ and $2 \mathbf{B}$ ). The surface as modified after only one cathodic scan could be indirectly functionalized with amino-acceptors (such as 1-aminoanthraquinone) or with 2bromomethylanthraquinone, making it possible to indirectly estimate, via grafting of $\pi$ acceptors, the apparent level of surface carboxylation $\left(\Gamma_{\mathrm{CO} 2} \approx 3 \pm 2 \times 10^{-9} \mathrm{~mol} \mathrm{~cm}^{-2}\right)$. FTIR analysis (absoption: $1780 \mathrm{~cm}^{-1}$, stretching $v(\mathrm{C}=\mathrm{O}) ; 1150 \mathrm{~cm}^{-1}, v(\mathrm{C}-\mathrm{O}) ; 950 \mathrm{~cm}^{-1}, \square(\mathrm{O}-\mathrm{H})$ confirmed the reactivity of $\mathrm{Cu}$ surfaces towards $\mathrm{CO}_{2}$. Lastly, the carboxylation procedure led to strongly hydrophilic interfaces (Figure 2C) that remained quite stable over time.

Figure 2

\section{Anodic Cu passivation via carboxylation}

The cathodic carboxylation process produces an efficient passivation of the $\mathrm{Cu}$ surface even when small amounts of electricity are applied, and reveals the high efficiency of the method. This is depicted in Figure 3. Therefore, after a single cathodic sweep down to -2.0 $\mathrm{V}$ (part $\mathrm{A}$ ) - reduction of $\mathrm{CO}_{2}$ at $\mathrm{Cu}$ according to step a, the subsequent anodic exploration can reach quite a positive potential $(+1.2 \mathrm{~V})$ without observing any corrosion of copper (part B). By contrast, a sharp step b is observed (first anodic scan only) which is assigned to the specific oxidation of the carboxylate interface, similar to a process observed [18] with gold, which is known not to corrode within this potential range. The integration of the peak allows the thickness of the carboxylate layer to be estimated (based on a one-electron process possibly assigned to the cleavage of the $\mathrm{Cu}-\mathrm{CO}_{2}$ bond). Coulometric values obtained over the course of several experiments then gave $\Gamma_{\mathrm{CO} 2}=1.5 \pm 2 \times 10^{-7}$ mole $\mathrm{cm}^{-2}$, which can be interpreted as the total disappearance of a thick carboxylated multilayer. This value can be compared with the amount of electricity injected in the course of the reduction (obtained according to A) which gives $\Gamma_{\mathrm{CO} 2}=4 \pm 1 \times 10^{-7}$ mole $\mathrm{cm}^{-2}$. The values are quite comparable and any discrepancy could be explained by the fast concomitant cathodic corrosion depicted in Figure 2B.

The anodic pulse allows the total decarboxylation of the metal and permits the regeneration of a clean $\mathrm{Cu}$ interface. Under these conditions, one might obtain strongly reactive copper interfaces (similarly to the spirit of reference [20] under a quite heavy process, generating $\mathrm{Cu}^{*}$ strongly active toward organic electrophiles such as $\mathrm{R}-\mathrm{Brs}$ ) in polar solvents after getting rid of any residual $\mathrm{CO}_{2}$ by simple bubbling of argon. This could be applied to the surface modification of other transition metals in which $\mathrm{CO}_{2}$ insertion is observed. 


\section{Conclusion}

The cathodic carboxylation of copper under the experimental conditions given above allow the reversible formation of thick $\left\{\mathrm{Cu}-\mathrm{CO}_{2}{ }^{-}-\mathrm{TMeA}^{+}\right\}$multi-layers which may be removed by a simple and efficient anodic process. The method could be considered as a facile process to temporarily store $\mathrm{CO}_{2}$ in a transition metal. Moreover, the efficient insertion of carbon dioxide in its reduced form (associated to a bulky ammonium cation or an alkaline metal cation like $\mathrm{Na}^{+}$or $\mathrm{K}^{+}$) during extensive electrolyses would provoke a deep burst and corrosion of the pristine $\mathrm{Cu}$ surface. The granular aspect of the produced surface can be seen as a conglomerate of micro-particles carboxylated (size $<100 \mathrm{~nm}$ ) at the surface which can be easily scratched off the transitory interface. The bursting of the interface by means of internal carboxylation concomitantly with the insertion of the salt makes it possible to extract the $\mathrm{Cu}$ nanoparticles, as depicted in Scheme1. This assumes a continuous degradation of the surface and depends on the applied potential. The generated copper boundaries showed a strong wetting ability. A pristine, clean and very active $\mathrm{Cu}$ surface, free of oxides, can easily be generated by anodic oxidation at $\mathrm{E}<+1.3 \mathrm{~V}$. The present electrochemical method could be compared with the purely organic approach proposed by Rieke [20] (reduction of $\mathrm{CuI}-\mathrm{PBu}_{3}$ using preformed lithium naphtalenide), allowing the formation of a copper interface reactive toward organic electrophiles.

Figure 3

\section{Scheme 1}

\section{Figure captions}

Figure 1 Cathodic carboxylation of smooth copper. Electrolyte: $\mathrm{DMF}+\mathrm{TMeABF}_{4}(0.1 \mathrm{M})$. $\mathrm{Cu}$ electrode surface area: $1.8 \mathrm{~mm}^{2}$. Scan rate: $100 \mathrm{mV} \mathrm{s}^{-1}$. Visualization of the first six cathodic sweeps up to $-2.2 \mathrm{~V}$, leading to an almost complete disappearance of the current.

Figure 2: Reduction of $\mathrm{CO}_{2}$ saturated at room temperature in $\mathrm{DMF}$ containing $\mathrm{TMeABF}_{4}(0.1$ M) at $-1.8 \mathrm{~V}$. Amount of electricity: $10^{-2} \mathrm{C} \mathrm{cm}^{-2}$. 
(A) and (B): Evidence of impressive corrosion of the metal, presumably provoked by the insertion of $\left\{\mathrm{CO}_{2}{ }^{-}, \mathrm{TMA}^{+}\right\}$that depends on the amount of electricity injected. White zones mark the original edges of pristine $\mathrm{Cu}$.

(C): Generation of hydrophilic surfaces by means of an efficient and dense carboxylation of copper. Right: water deposited on smooth copper (no wetting). Left: water droplets on the carboxylated surface (extensive wetting).

Figure 3: Carboxylation of smooth copper micro-electrode. Area: $3.2 \mathrm{~mm}^{2}$. Electrolyte: DMF + $\mathrm{TMeABF}_{4}(0.1 \mathrm{M})$. Scan rate: $50 \mathrm{mV} \mathrm{s}^{-1}$. (A) First cathodic scan immediately followed by (B) showing two successive recurrent oxidation sweeps up to $+1.5 \mathrm{~V}$ within the interval $0 \mathrm{~V}$ to $+1.5 \mathrm{~V}$ (beware that cathodic and anodic potential scales are different).

Scheme 1: Cathodic carboxylation of copper followed by swelling and interface bursting with emission of micro-nodules assigned to functionalized $\mathrm{Cu}$ NPs. The black profiles correspond to thickly carboxylated $\mathrm{Cu}$ interfaces.

\section{References}

[1] D. Pletcher, The cathodic reduction of carbon dioxide-What can it realistically achieve? A mini review, Electrochem. Commun. 61 (2015) 97.

[2] I. Ganesh, Electrochemical conversion of carbon dioxide into renewable fuel chemicals The role of nanomaterials and the commercialization, Renewable and Sustainable Energy Reviews 59 (2016) 1269.

[3] J. H. Q. Lee, S. J. L. Lauw, R. D. Webster, The electrochemical reduction of carbon dioxide $\left(\mathrm{CO}_{2}\right)$ to methanol in the presence of pyridoxine (vitamin $\mathrm{B}_{6}$ ), Electrochem. Commun. 64 (2016) 69.

[4] W. Lv, R. Zhang, P. Gao, L. Lei, Studies on the faradaic efficiency for electrochemical reduction of carbon dioxide to formate on tin electrodes, J. Pow. Sources 253 (2014) 276.

[5] O. Scialdone, A. Galia, G. Nero, F. Proietto, S. Sabatino, B. Schiavo, Electrochemical reduction of carbon dioxide to formic acid at a tin cathode in divided and undivided cells: effect of carbon dioxide pressure and other operating parameters, Electrochim. Acta 199 (2016) 332.

[6] Z-L. Wang, C. Li, Y. Yamauchi, Nanostructured non precious metal catalysts for electrochemical reduction of carbon dioxide, Nano Today, 11 (2016) 373.

[7] Q. Jianping,T. Juntao, S. Jie, W. Cuiwei, Q. Mengqian, H. Zhiqiao, C. Jianmeng, S. Song, Preparation of a silver electrode with a three-dimensional surface and its performance in the electrochemical reduction of carbon dioxide, Electrochim. Acta 203 (2016) 99. 
[8] H. Khoshro, H. R. Zare, A. Gorji, M. Namazian, A study of the catalytic activity of symmetric and unsymmetric macrocyclic $\left[\mathrm{N}_{4}{ }^{2-}\right.$ ] coordinated nickel complexes for electrochemical reduction of carbon dioxide, Electrochim. Acta 117 (2014) 62.

[9] S. Bashir, Sk.S. Hossain, S. ur Rahman, S. Ahmed, A-A. Amir, M. M. Hossain, Electrocatalytic reduction of carbon dioxide on $\mathrm{SnO}_{2} / \mathrm{MWCNT}$ in aqueous electrolyte solution, J. CO2 Utilization 16 (2016) 346.

[10] A. Q. Fenwick, J. M. Gregoire, O. R. Luca, Electrocatalytic reduction of nitrogen and carbon dioxide to chemical fuels: challenges and opportunities for a solar fuel device, Special issue on Artificial Photosynthesis, Journal of Photochemistry \& Photobiology, B: Biology 152 (2015) A 47.

[11] A. Grace, S. Y. Choi, M. Vinoba, M. Bhagiyalakshmi, D. H. Chu, Y. Y. Yoon, S. C. Nam, S. K. Jeong, Electrochemical reduction of carbon dioxide at low overpotential on a polyaniline/ $\mathrm{Cu}_{2} \mathrm{O}$ nanocomposite based electrode, Appl. Energy 120 (2014) 85.

[12] M. García, M. J. Aguirre, G. Canzi, Kubiak, P. Clifford, M. Ohlbaum, M. Isaacs, Electro and photoelectrochemical reduction of carbon dioxide on multimetallic porphyrins/polyoxotungstate modified electrodes, Electrochim. Acta 115 (2014) 146.

[13] J. Qiao, M. Fan, Y. Fu, Z. Bai, C. Ma, Y. Liu, X. Zhou, Highly-active copper oxide/copper electrocatalysts induced from hierarchical copper oxide nanospheres for carbon dioxide reduction reaction, Electrochim. Acta. 153 (2015) 559.

[14] B. Kumar, J. P. Brian, V. Atla, S. Kumari, K. A. Bertram, R. T. White, J. M. Spurgeon, New trends in the development of heterogeneous catalysts for electrochemical $\mathrm{CO}_{2}$ reduction, C1 Cat. Chem. Catalysis Today. 270 (2016) 9.

[15] J. Simonet, Conditions for a large sequestration of carbon dioxide into glassy carbon. generation of carbon carboxylate versatile material, Electrochem. Commun. 21 (2012) 22.

[16] V. Jouikov, J. Simonet, Efficient cathodic carboxylation of graphene, Electrochem. Commun. 43 (2014) 67.

[17] J. Simonet, Insertion of $\mathrm{CO}_{2}$ into silver in a large extent, Electrochem. Commun. 58 (2015) 11.

[18] V. Jouikov, J. Simonet, Cathodic carboxylation of gold in thick $\mathrm{Au}-\mathrm{CO}_{2}$ layers. A model for a reversible electrochemical sequestration of $\mathrm{CO}_{2}$, Electrochem. Comm $\mathbf{5 9}$ (2015) 40.

[19] M. Jitaru, Solubility of carbon dioxide into usual organic solvents, J. Univ. Chem. Tecnol. Metall 42 (2007) 333

[20] R. D. Rieke, D. E. Stack, B. T. Dawson, T.-C. Wu, Preparation and chemistry of the active copper species derived from $\mathrm{CuI}-\mathrm{PBu}_{3}, \mathrm{CuI}-\mathrm{PPh}_{3}$, and $\mathrm{CuCN}-\mathrm{nLiX}$ complexes, J. Org. Chem 58 (1993) 2483. 


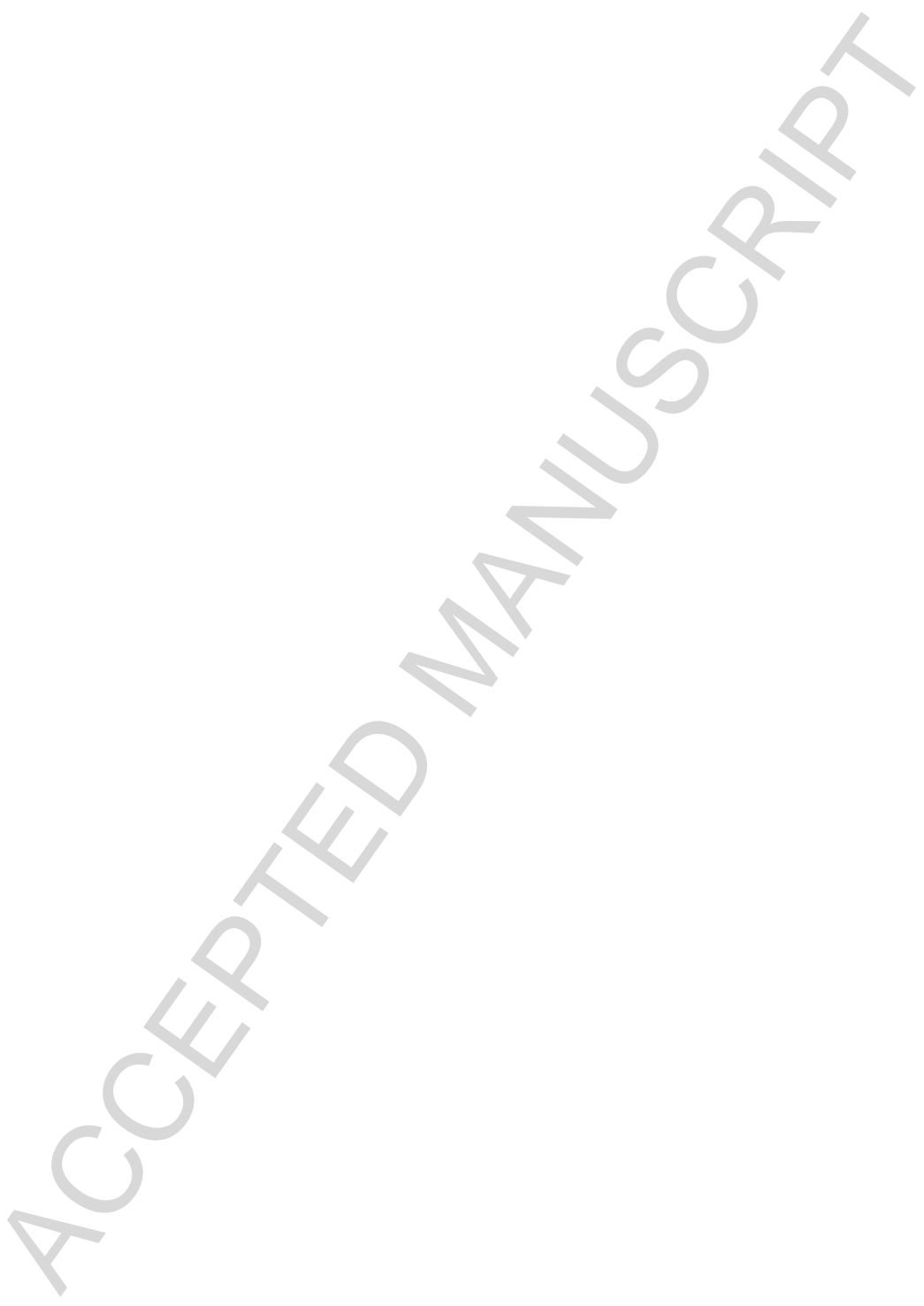




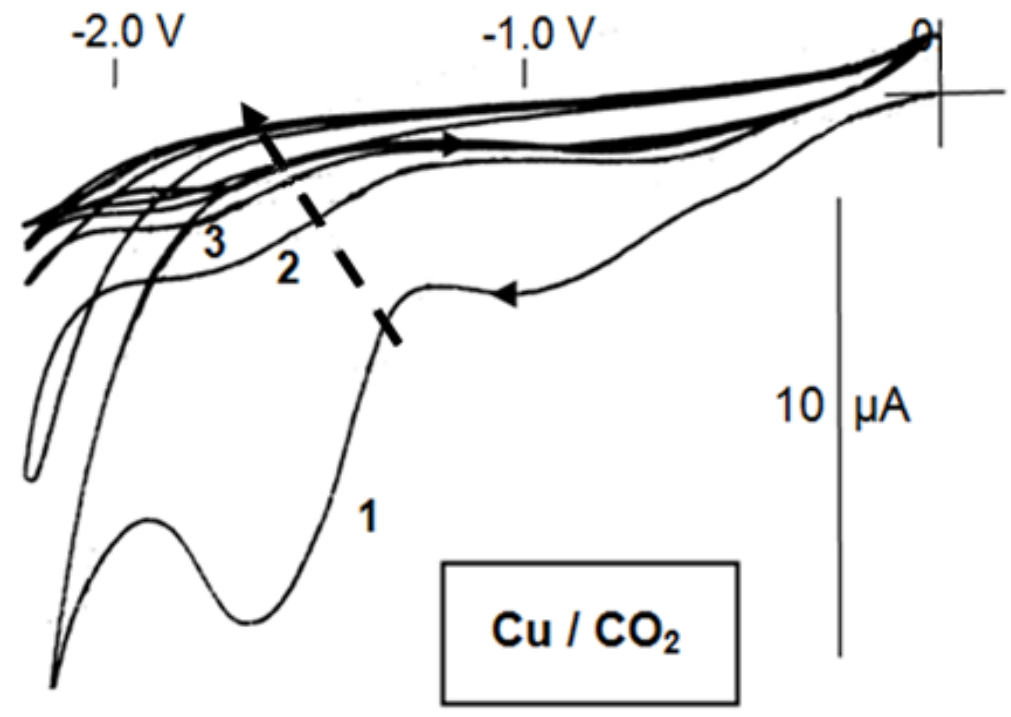

Figure 1 


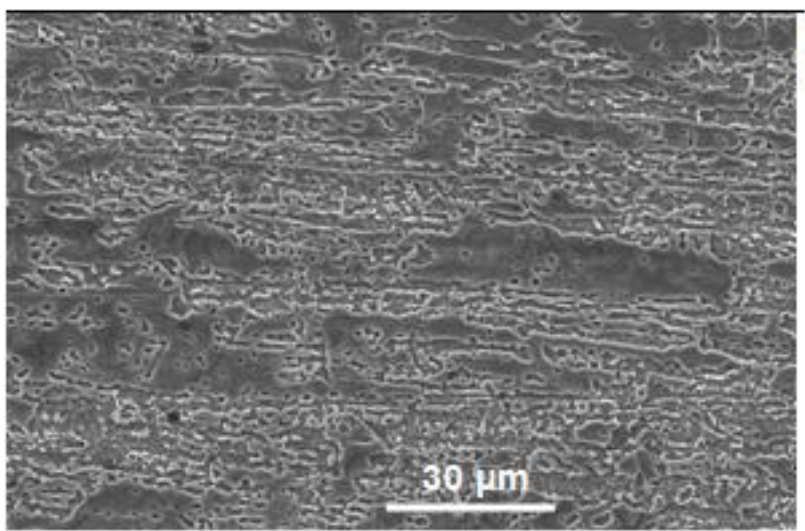

A
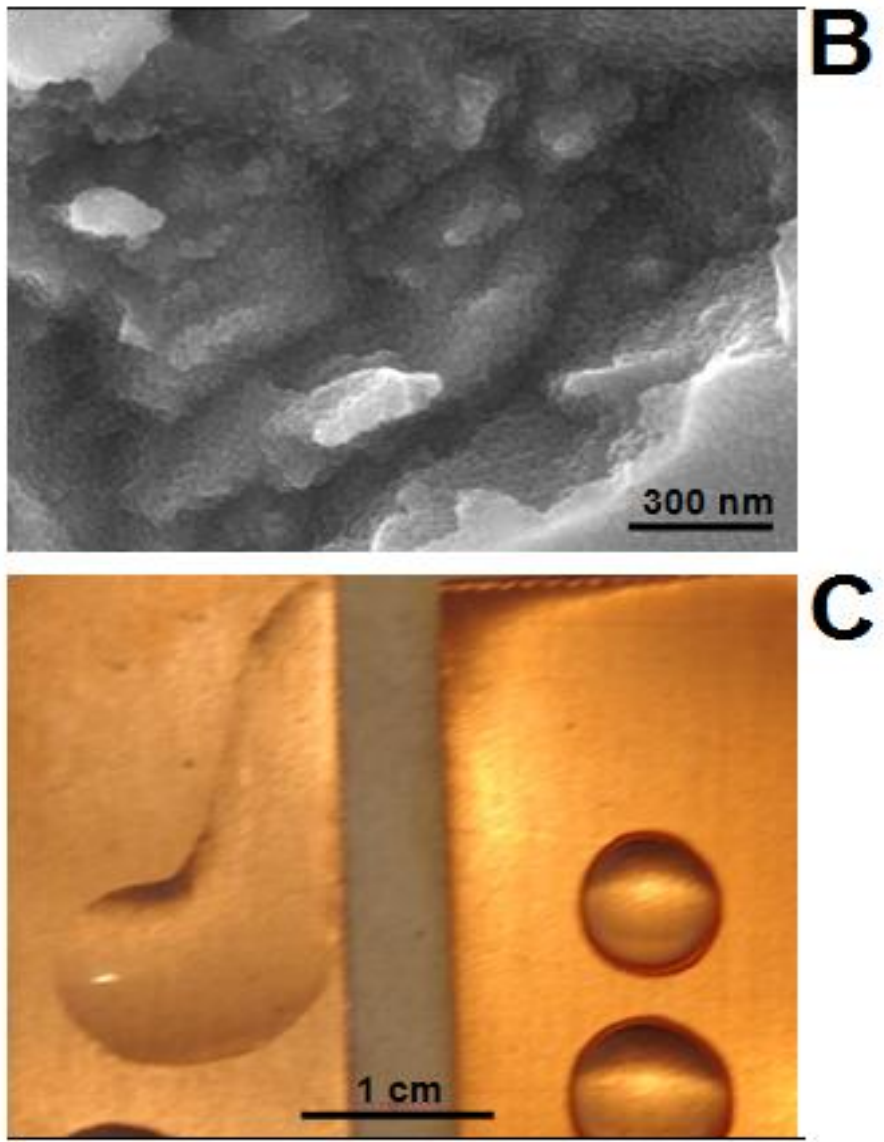

Figure 2 


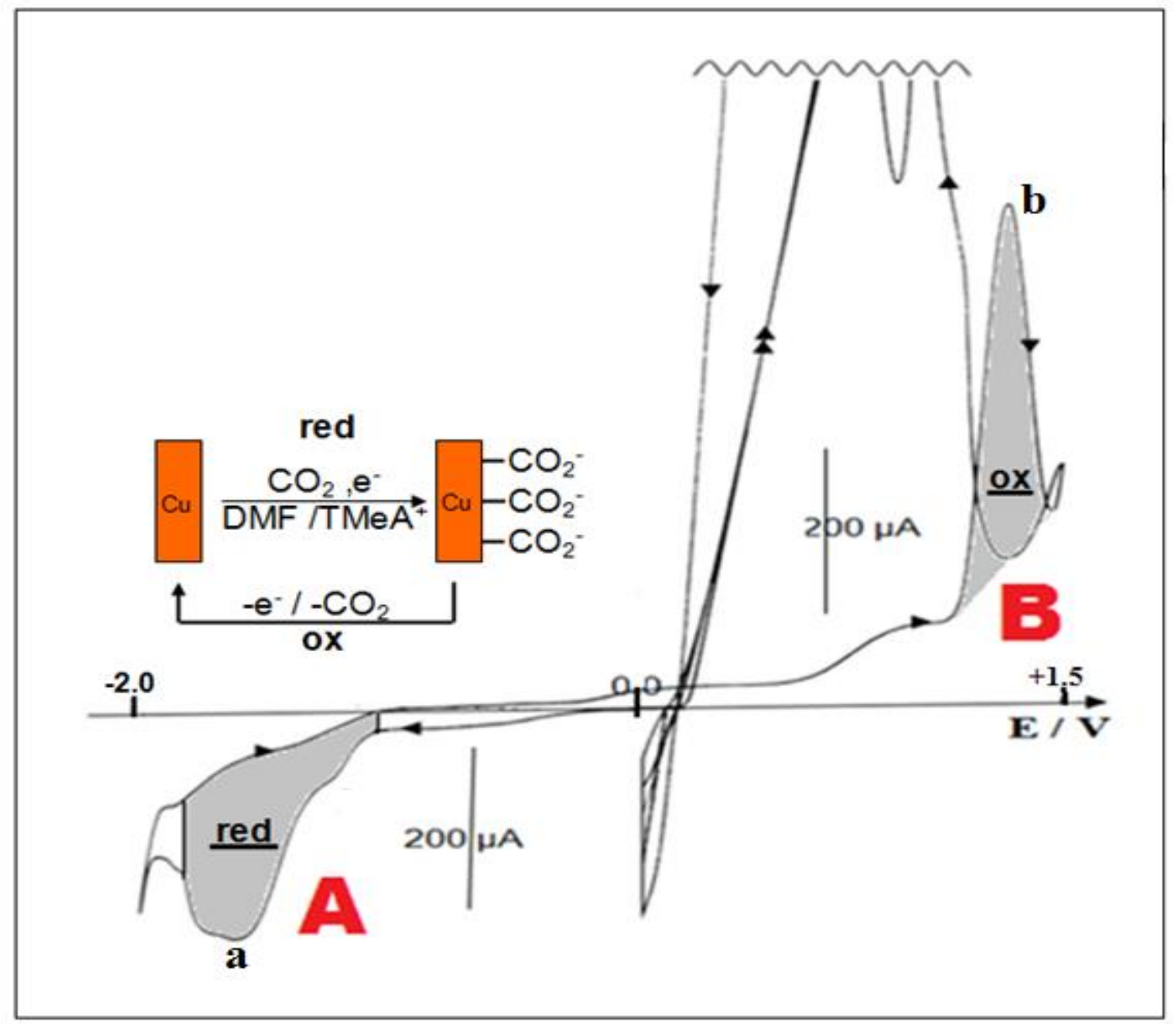

Figure 3 


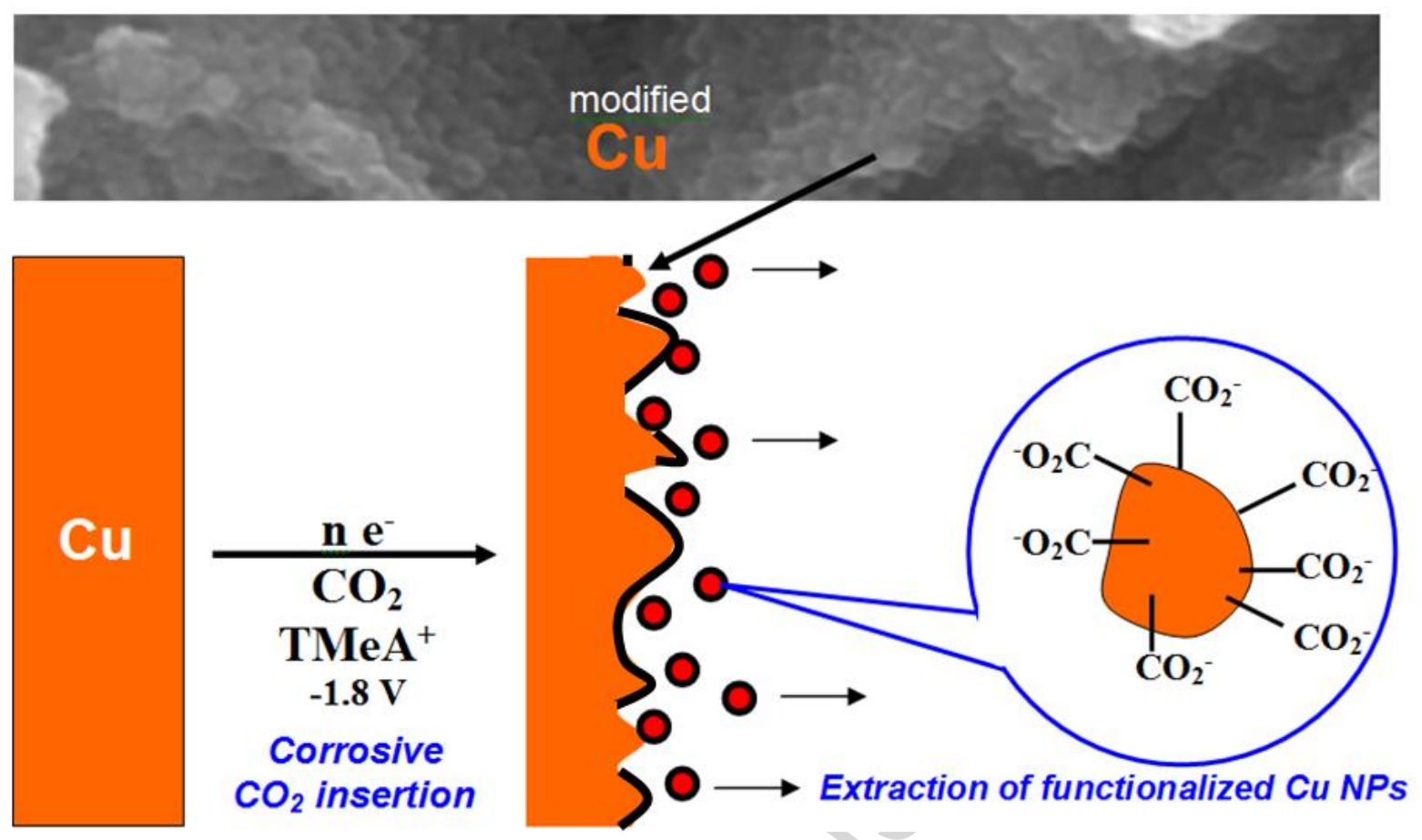

Scheme 1 


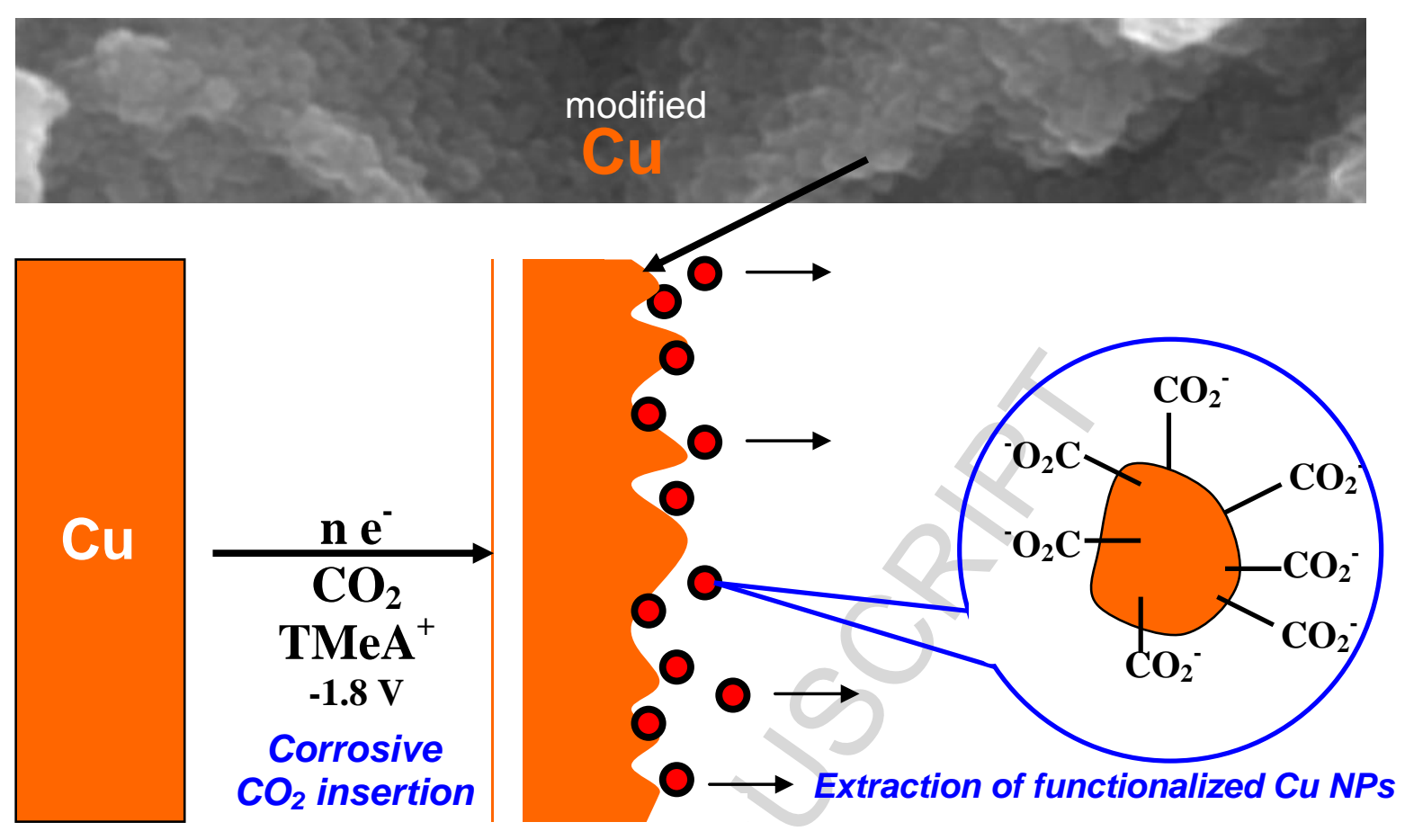

Graphical Abstract 


\section{Highlights}

- Copper is chemically modified by cathodic insertion of carbon dioxide.

- Experimental conditions permit the insertion of the $\mathrm{CO}_{2}$ anion radical.

- A "reversible" carboxylation/de-carboxylation process is revealed.

- Coverage of the $\mathrm{Cu}$ surface by carboxylates results in a strongly hydrophilic material.

- Chemical insertion of the reduced form of $\mathrm{CO}_{2}$ causes bursting of the $\mathrm{Cu}$ metal. 